\title{
Penerapan Tindakan Senam Hipertensi Untuk Menurunkan Tekanan Darah Pada Pasien Lansia
}

\author{
Istianti $^{1^{*}}$, Dwi Fijianto ${ }^{2}$, \\ ${ }^{1,2}$ Program Studi Diploma Tiga Keperawatan, Universitas Muhammadiyah Pekajangan \\ Pekalongan, Indonesia \\ *email: istiistianti6@gmail.com
}

\begin{abstract}
Hypertension in the elderly is those who experience an increase in systolic blood pressure above $140 \mathrm{mmHg}$ and diastolic pressure above $90 \mathrm{mmHg}$. This paper aims to apply hypertension exercises to lower blood pressure in the elderly.Two elderly people with hypertension in Johosari Village, Kandeman, Batang were taken as the subject. The result showed both have experienced a decrease in pain and blood pressure. At the visit, a pain scale was 6, TD: $160 / 90 \mathrm{mmHg}$ and it has decreased into 1, and TD: $120 / 80 \mathrm{mmHg}$ at the last visit on the first case. Meanwhile, on the second case, a pain scale was 7, TD: 170/90 $\mathrm{mmHg}$ in the first visit and it has decreased into 1, TD: $120 / 90 \mathrm{mmHg}$ in the last visit. Therefore, it could be concluded the exercises are effectively applied to lowe blood pressure on the elderly. And, it is expected as one of the ways to reduce blood pressure on the elderly with hypertension.
\end{abstract}

Keywords: Hypertension, The elderly, Hypertension exercises

\begin{abstract}
Abstrak
Hipertensi pada lansia adalah lansia yang mengalami peningkatan tekanan darah sistolik diatas $140 \mathrm{mmHg}$ dan tekanan diastolik di atas $90 \mathrm{mmHg}$.Tindakan untuk menurunkan tekanan darah salah satunya adalah dengan senam hipertensi.Senam hipertensi mampu untuk menurunkan tekanan darah.Tujuan Karya Tulis Ilmiah ini adalah untuk mengaplikasikan tindakan senam hipertensi untuk menurunkan tekanan darah pada lansia yang mengalami hipertensi. Metode Karya Tulis Ilmiah ini adalah penerapan tindakan senam hipertensi pada lansia.Subyek studi kasus yang digunakan dua lansia yang mengalami hipertensi di desa Johosari Kecamatan Kandeman kabupaten Batang. Hasil penerapan menunjukkan selama 7 kali kunjungan dua lansia mengalami penurunan nyeri dan penurunan tekanan darah, pada kasus satu kunjungan pertama skala nyeri 6, TD: $160 / 90 \mathrm{mmHg}$ dan kunjungan ketujuh skala nyeri menjadi 1, TD: $120 / 80 \mathrm{mmHg}$, sedangkan kasus dua kunjungan pertama skala nyeri 7, TD: $170 / 90 \mathrm{mmHg}$ dan kunjungan ketujuh skala nyeri menjadi 1, TD: 120/90 mmHg.Kesimpulan dari studi kasus ini menunjukkan senam hipertensi efektif digunakan untuk menurunkan tekanan darah pada lansia.Saran dari penulis diharapkan senam hipertensi dapat dijadikan sebagai tindakan untuk menurunkan tekanan darah pada lansia hipertensi.
\end{abstract}

Kata kunci: Hipertensi, lansia, senam hipertensi

\section{Pendahuluan}

Hipertensi merupakan faktor resiko utama penyakit kardiovaskuler yang menyebabkan kematian nomer 3 terbanyak di dunia dan merupakan penyebab kematian tertinggi di Indonesia setelah stroke dan tuberculosis. Kematian akibat hipertensi mencapai 6,8\% dari populasi kematian di Indonesia. Hipertensi pada lansia merupakan tekanan darah dengan tekanan sistolik di atas $140 \mathrm{mmHg}$ dan tekanan diastolik di atas $90 \mathrm{mmHg}$ [1]. Hipertensi merupakan suatu keadaan dimana seseorang 


\section{Prosiding Seminar Nasional Kesehatan Lembaga Penelitian dan Pengabdian Masyarakat Universitas Muhammadiyah Pekajangan Pekalongan}

mengalami peningkatan tekanan darah diatas normal yang mengakibatkan peningkatan angka kesakitan (morbiditas) dan angka kematian (mortalitas).

Penelitian [2] mengungkapkan ada banyak faktor yang menyebabkan hipertensi antara lain genetik, pola makan, aktivitas fisik, stress, serta farmakologi. [2] menjelaskan bahwa tekanan darah meningkat disebabkan karena proses penuaan dan terjadi perubahan sistem kardiovaskuler baik secara struktural maupun fisiologis, pola makan dan gaya hidup seperti kurang berolahraga. Tanda dan gejala hipertensi dapat terjadi pada lansia, [3] menjelaskan tanda gejala yang dialami penderita hipertensi diantaranya sakit kepala, kelelahan, pusing, gelisah, sesak nafas, mual, kelemahan otot, kesadaran menurun.

Tanda gejala yang tidak diatasi dapat menyebabkan komplikasi, tanda gejala yang tidak diatasi dapat menyebabkan berbagai macam komplikasi. [3] menjelaskan komplikasi yang dapat terjadi pada penyakit hipertensi diantaranya penyakit jantung seperti gagal jantung, penyakit pembuluh darah otak seperti perdarahan otak, stroke, penyakit koronaria dan dimensia. Tanda gejala pada hipertensi yang tidak dilakukan penanganan dapat menyebabkan komplikasi dan masalah yang serius. Penanganan yang tepat pada hipertensi dapat menurunkan resiko komplikasi. Beberapa tindakan menurut [3] ada beberapa tindakan yaitu dengan tindakan farmakologi dan non farmakologis.

Penelitian yang dilakukan [3] menjelaskan bahwa senam hipertensi dapat menurunkan tekanan darah. Sebelum dilakukan senam hipertensi tekanan darah tinggi dan setelah dilakukan senam hipertensi tekanan darah menjadi turun. Penelitian yang dilakukan [4] menghasilakan bahwa senam hipertensi dapat menurunkan tekanan darah. Berdasarkan penelitian menurut [3]) dan [4] bahwa senam hipertensi efektif untuk menurunkan tekanan darah pada lansia yang menderita hipertensi. Berdasarkan latar belakang di atas peneliti tertarik untuk menerapkan intervensi senam hipertensi pada lansia yang menderita hipertensi. Peneliti berharap dengan diterapkan intervensi senam hipertensi dapat digunakan sebagai sarana pengendalian secara non farmakologis untuk menurunkan tekanan darah pada lansia yang mengalami hipertensi.

\section{Metode}

Metode yang dilakukan pada artikel ilmiah ini adalah metode studi kasus. Lokasi pelaksanaan penelitian ini dilaksanakan di Desa Johosari Kabupaten Batang. Penelitian ini mengguakan subyek individu yang diamati secara mendalam dan dilakukan asuhan keperawatan secara komprehensif. Subyek studi kasus yang digunakan yaitu 2 (dua) pasien lansia, pasien yang menderita hipertensi dengan usia 60 tahun keatas. Sampel dalam penelitian ini adalah 2 lansia yang menderita hipertensi dengan usia 60 tahun keatas di wilayah Desa Johosari Kabupaten Batang dengan kriteria Inklusi: lansia yang mengalami hipertensi dengan kategori hipertensi sedang sistolik 160-179 mmHg, lansia yang kooperatif, lansia yang bersedia menjadi responden. Sedangkan kriteria esklusi pada studi kasus yaitu: lansia yang bedrest, lansia dengan gangguan penglihatan, lansia dengan gangguan musculoskeletal, lansia hipertensi yang sudah konsumsi obatobatan hipertensi. 


\section{Prosiding Seminar Nasional Kesehatan 2021 Lembaga Penelitian dan Pengabdian Masyarakat Universitas Muhammadiyah Pekajangan Pekalongan}

\section{Hasil dan Pembahasan Hasil}

Hasil studi kasus didapatkan bahwa implementasi pada kasus 1 dan kasus 2 yang sudah penulis lakukan pada pasien hipertensi adalah memberikan tindakan senam hipertensi. Senam hipertensi diberikan pada lansia penderita hipertensi untuk menurunkan tekanan darah. Senam hipertensi dilakukan selama 30 menit dan dilakukan seminggu 2 kali. Hal ini sesuai dengan penelitian [4] yang menyatakan salah satu metode keperawatan untuk menurunkan tekanan darah pada penderita hipertensi yaitu dengan senam hipertensi. Aadapun implementasi keperawatan keperawatan senam hipertensi yang dilakukan oleh [4] senam hipertensi merupakan olahraga yang salah satunya bertujuan untuk penderita hipertensi dan usia lanjut untuk mengurangi berat badan dan mengelola stress atau faktor yang mempertinggi hipertensi. Penelitian menurut [5] senam hipertensi merupakan olahraga yang bertujuan untuk menurunkan tekanan darah, menegola stres dan faktor yang mempertinggi hipertensi. Manfaat senam hipertensi yaitu untuk mengurangi berat badan pada penderita hipertensi, memberikan pemikiran yang positif kepada lansia sehingga dapat meningkatkan aliran darah serta pasokan oksigen kedalam otot jantung [6]. Penulis melakukan pemberian tindakan senam hipertensi sesuai dengan yang diterapkan oleh [6] yaitu sebelum diberikan tindakan senam hipertensi penulis melakukan pengukuran tekanan darah terlebih dahulu, setelah itu posisikan pasien untuk berdiri dan melakukan tindakan senam hipertensi sesuai SOP yang diajarkan yang dilakukan selama 30 menit dan dilakukan seminggu 2 kali. Berdasarkan yang penulis dapatkan selama tindakan keperawatan menurut [4], [5] dan [6] bahwa tindakan senam hipertensi efektif untuk menurunkan tekanan darah pada pasien hipertensi.

\section{Pembahasan}

Hasil studi kasus menunjukan bahwa tindakan senam hipertensi dapat menurunkan tekanan darah, hasil studi kasus sesuai dengan penelitian menurut [6], yang menjelaskan bahwa hipertensi merupakan tekanan darah persisten atau terusmenerus sehingga melebihi batas normal dimana sistolik diatas $140 \mathrm{mmHg}$ dan tekanan diastole di atas $90 \mathrm{mmHg}$. Menurut [7], hipertensi adalah suatu keadaan dimana seseorang mengalami peningkatan tekanan darah diatas normal yang mengakibatkan peningkatan angka kesakitan (mordibitas) dan angka kematian (mortalitas). Menurut [8], penyakit hipertensi atau tekanan darah tinggi merupakan salah satu penyakit tidak menular biasanya berpengaruh pada organ lain yaitu stroke dari otak dan jantung koroner dari pembuluh darah jantung dan otot jantung.

Hasil studi kasus menunjukan bahwa tindakan senam hipertensi dapat menurunkan tekanan darah, hasil studi kasus sesuai dengan penelitan menurut [8], yang menjelaskan bahwa penyebab terjadinya hipertensi terdiri dari berbagai faktor. Faktor resiko yang dapat menyebabkan hipertensi adalah stress, kegemukan, merokok, hipernatriumia. Penyebab hipertensi dapat dibedakan menjadi dua yaitu hipertensi primer dan hipertensi sekunder, hipertensi primer merupakan tekanan darah tinggi yang disebabkan karena retensi air dan garam yang tidak normal, obesitas, emosi yang terganggu dan merokok. Sedangkan hipertensi sekunder merupakan tekanan darah 


\section{Prosiding Seminar Nasional Kesehatan Lembaga Penelitian dan Pengabdian Masyarakat Universitas Muhammadiyah Pekajangan Pekalongan}

tinggi yang disebabkan karena penyakit kelenjar adrenal, penyakit ginajl,peningkatan tekanan intra cranial, yang disebabkan tumor otak.

Hasil studi kasus menunjukan bahwa tindakan senam hipertensi dapat menurunkan tekanan darah, hasil studi kasus sesuai dengan penelitian menurut [8], yang menjelaskan bahwa Komplikasi yang dapat terjadi pada penyakit hipertensi diantaranya penyakit pembuluh darah otak seperti stroke, perdarahan otak, penyakit jantung seperti gagal jantung, angina pectoris, infrak miocard akut (IMA) Penyakit ginjal seperti gagal ginjal, penyakit mata seperti perdarahan retina, dan oedema pupil. Komplikasi hipertensi yang menetap dapat menyebabkan kerusakan pembuluh darah otak, ginjal dan jantung. Hipertensi selain berdampak pada kualitas hidup juga dapat mengakibatkan kematian.

Hasil studi kasus menunjukan bahwa tindakan senam hipertensi dapat menurunkan tekanan darah, hasil studi kasus sesuai dengan penelitian menurut [9] yang menjelaskan bahwa Senam hipertensi merupakan olahraga yang ditunjukkan untuk penderita hipertensi dan usia lanjut untuk mengurangi berat badan dan mengelola stress (faktor yang mempertinggi hipertensi yang dilakukan selama 30 menit dan dilakukan seminggu minimal dua kali. Tujuan dari senam hipertensi adalah untuk meningkatkan aliran darah dan pasokan oksigen ke dalam otot-otot dan rangka yang aktif khusunya terdapat otot jantung sehingga dapat menurunkan tekanan darah. [9] menjelaskan bahwa senam hipertensi merupakan olahraga yang salah satunya bertujuan untuk meningkatkan aliran darah dan pasokan oksigen kedalam otot-otot dan rangka yang aktif khususnya terhadap otot jantun. Manfaat senam hipertensi yaitu untuk mengurangi berat badan pada penderita hipertensi, memberikan pemikiran yang positif kepada lansia sehingga dapat meningkatkan aliran darah serta pasokan oksigen kedalam otot jantung.

\section{Kesimpulan}

Dari hasil penelitian dapat disimpulkan pada studi kasus ini bahwa senam hipertensi dapat menurunkan tekanan darah pada lansia. Pada kasus satu kunjungan pertama skala nyeri 6, TD: 160/90 $\mathrm{mmHg}$ dan kunjungan ketujuh skala nyeri menjadi 1, TD: $120 / 80 \mathrm{mmHg}$. Pada kasus kedua kunjungan pertama skala nyeri 7, TD: 170/90 $\mathrm{mmHg}$ dan kunjungan ketujuh skala nyeri menjadi 1, TD: 120/90 mmH. Hasil studi kasus dapat menurunkan tekanan darah diharapakan senam hipertensi ini dapat menjadi terapi non farmakologis pada lansia yang mengalami hipertensi, dapat digunakan untuk menambah literatur mengenai asuhan keperawatan pada lansia yang mengalami hipertensi, dapat digunakan untuk menambah ilmu pengetahuan, pengalaman, dan kemampuan penulis dalam melakukan studi kasus pada pasien lansia hipertensi, dapat digunakan sebagai bahan pertimbangan untuk tindakan keperawatan untuk menurunkan hipertensi.

\section{Referensi}

[1] Ardiansyah, M, "Medikal Bedah Untuk Mahasiswa, " Jogjakarta, Indonesia: Diva Press, 2012.

[2] Damajanty, "Pengaruh Senam Hipertensi Terhadap Penurunan Tekanan Darah di Desa Gondangsari Kelurahan Pajang Surakarta," Jurnal Kesehatan Kusuma 


\section{Prosiding Seminar Nasional Kesehatan 2021 Lembaga Penelitian dan Pengabdian Masyarakat Universitas Muhammadiyah Pekajangan Pekalongan}

Husada-Juli 2017. Vol. 10. N0. 2 Juli 2014. Di ambil dari https://scholar.google.co.id/

[3] Izhar, "Pengaruh senam lansia terhadap tekanan darah di panti social tresna werdha budi luhur jambi," Jurnal ilmiah universitas batang hari Jambi. Vol.17 No. 1. Juni 2017. Diambil dari https://scholar.google.co.id

[4] Ode, La, Sharif, "Asuhan Keperawatan Gerontik," Yogyakarta: Nuha Medika, 2017.

[5] Totok \& Hernawan, "Pengaruh senam hipertensi lansia terhadap penurunan tekanan darah lansia dengan hipertensi di Panti Werdha Drama Bhakti Kelurahan Pajang Surakarta," Jurnal Kesehatan. Vol. 10, No. 1. Juni 2017. Di ambil dari https://scholar.google.co.id/.

[6] Totok \& Rosyid, "Pengaruh senam hipertensi lansia terhadap penurunan tekanan darah lansia dengan hipertensi di Panti Werdha Drama Bhakti Kelurahan Pajang Surakarta," Jurnal Kesehatan. Vol. 10. No. 1. Juni 2017. Di ambil dari https://scholar.google.co.id/

[7] Tristyaningsih, "Pengaruh Senam Hipertensi Terhadap Penurunan Tekanan Darah di Desa Blembem Wilayah Kerja Puskesmas Gondangrejo 2011," Diambil dari http://scholar.googleusercontent.com/scholar?=cache:ixA36w3DBwQJ:scholar.go ogle.com/+senam+hipertensi+pada+lansia\&hl=id\& $\mathrm{sdt}=0,5$

[8] Sumartini \& Zulkifli, "Pengaruh senam hipertensi lansia terhadap tekanan darah lansia dengan hipertensi di Wilayah Kerja Puskesmas Cakranegara Kelurahan Turida Tahun 2019," Jurnal Keperawatan. ISSN 2685-0710 Vol.1 No. 2 Oktober 2019. Diambil dari https://scolar.google.co.id/.

[9] Zulkifli, "Pengaruh senam hipertensi lansia terhadap tekanan darah lansia dengan hipertensi di Wilayah Kerja Puskesmas Cakranegara Kelurahan Turida Tahun 2019," Jurnal Keperawatan. ISSN 2685-0710 Vol.1 No. 2. Oktober 2019. Diambil dari https://scolar.google.co.id/ 